\title{
Geophysical imaging of porosity variations in the Danish North Sea chalk
}

\author{
Tanni Abramovitz
}

More than $80 \%$ of the present-day oil and gas production in the Danish part of the North Sea is extracted from fields with chalk reservoirs of late Cretaceous (Maastrichtian) and early Paleocene (Danian) ages (Fig. 1). Seismic reflection and inversion data play a fundamental role in mapping and characterisation of intra-chalk structures and reservoir properties of the Chalk Group in the North Sea. The aim of seismic inversion is to transform seismic reflection data into quantitative rock properties such as acoustic impedance (AI) that provides information on reservoir properties enabling identification of porosity anomalies that may constitute potential reservoir compartments. Petrophysical analyses of well log data have shown a relationship between AI and porosity. Hence, AI variations can be transformed into porosity variations and used to support detailed interpretations of porous chalk units of possible reservoir quality.

This paper presents an example of how the chalk team at the Geological Survey of Denmark and Greenland (GEUS) integrates geological, geophysical and petrophysical information, such as core data, well log data, seismic 3-D reflection and AI data, when assessing the hydrocarbon prospectivity of chalk fields.

\section{Chalk}

Chalk is a pelagic carbonate sediment, formed from settling of calcareous phytoplankton remains (i.e. coccoliths). The North Sea chalk is practically a monomineralic carbonate reservoir rock that consists of $96-99 \%$ calcite $\left(\mathrm{CaCO}_{3}\right)$, opal (radiolarians, diatoms and sponge spicules) and small amounts of clay minerals washed into the basin from land (Håkansson et al. 1974; Hancock 1975). As a reservoir rock, chalk is characterised by high porosity (25-50\%) and low permeability (0.1-10 millidarcies, mD; Jørgensen \& Andersen 1991). Depending on permeability, chalk can be either a reservoir or a seal.

Due to the dominating calcitic nature of chalk, a robust empirical correlation exists between AI and total porosity (PHIT). Hence, AI values can be transformed to PHIT and the relationship can be visualised by cross-plots of PHIT versus AI. Variations in porosity obtained from inverted seismic data reflect changes in clay content or clay mineralogy, pore geometry, pore fluid and fracture characteristics (Anderson
1999). Using seismic attributes, it is also possible to distinguish between clean porous chalk with high-amplitude continuous reflectivity and clean tight chalk with low-amplitude discontinuous reflectivity. Furthermore, the gamma-ray logsonic-log correlation method can be used to distinguish between reservoir and non-reservoir intervals within the Chalk Group. The gamma-ray log can distinguish clean chalk intervals from more clay-rich chalk intervals, and the sonic $\log$ can be used as a porosity indicator. The gamma-ray log sonic-log correlation method has been developed because gamma-ray and sonic logs are the most commonly available log types for North Sea wells (Britze et al. 2000).

\section{Multi-disciplinary approach}

\section{The Kraka Field}

An example from the Kraka Field in the southern part of the Salt Dome province in the Danish North Sea illustrates how a multidisciplinary approach can be used to identify and delineate porosity anomalies in the Maastrichtian reservoir interval. A combination of detailed seismic interpretation,

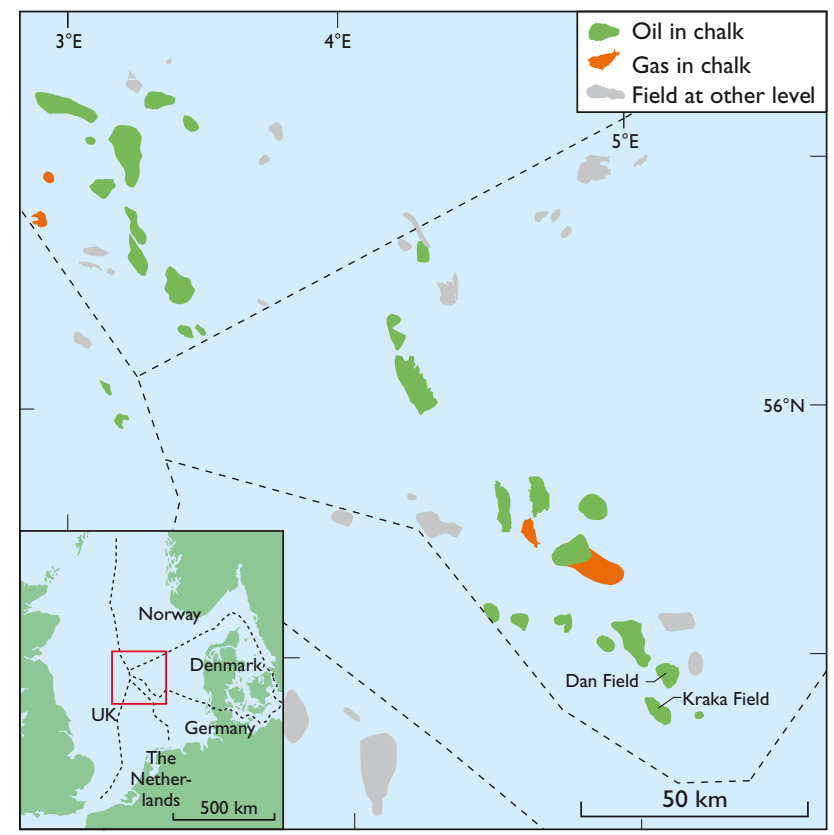

Fig. 1. Map of the central part of the North Sea, showing the distribution of oil- and gasfields. Modified from Vejbæk et al. (2007). 


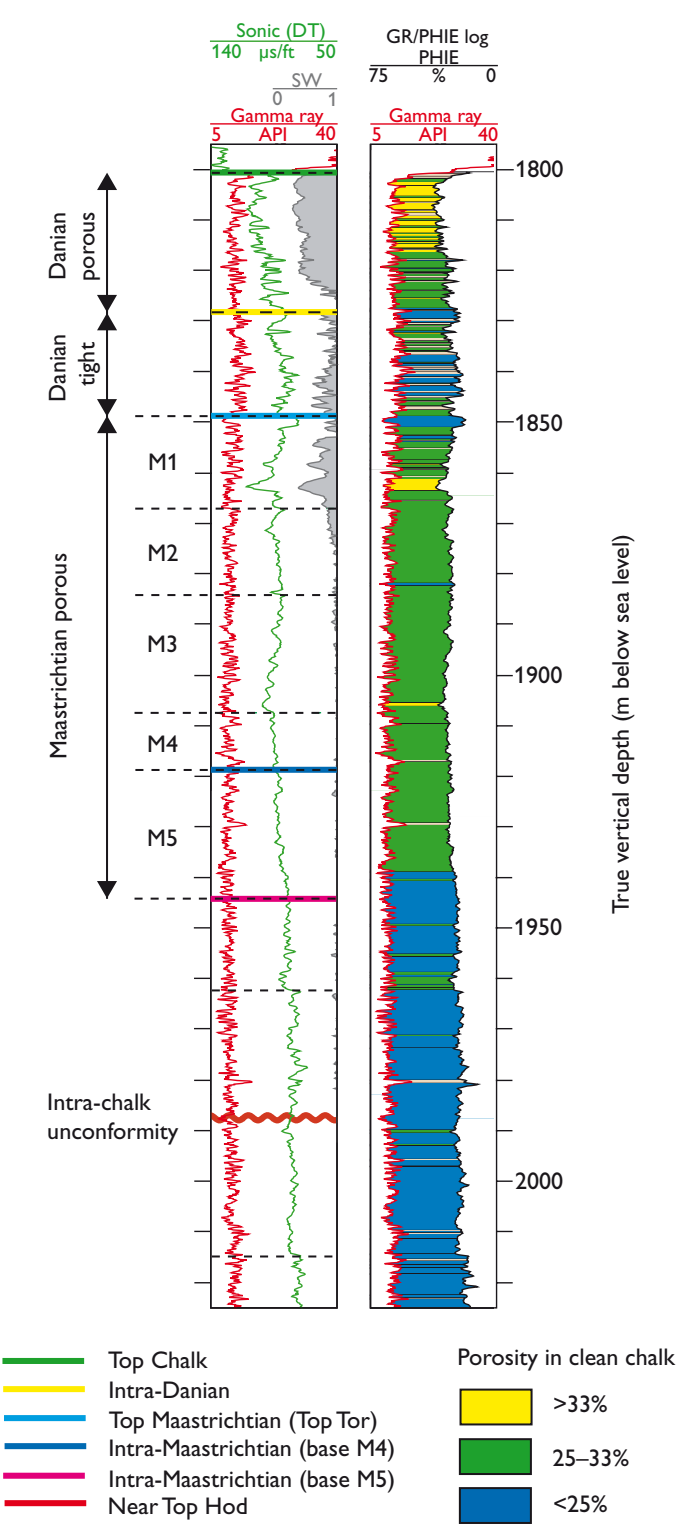

Fig. 2. GR-DT log for the Anne-3 well, Kraka Field. Gamma-ray, sonic, effective porosity and water saturation log curves are shown for the different reservoir units of the Danian-Maastrichtian reservoir interval. High GR chalk is shown in brown. DT, sonic; GR, gamma ray; $\mathbf{S W}$, total water saturation; PHIE, effective porosity. Modified from Klinkby et al. (2005).

analysis of AI variations obtained from seismic inversion data, stratigraphic log correlation, petrophysical log analysis and rock physics analysis was used.

The Kraka Field is a $60 \mathrm{~km}^{2}$ anticlinal structure with a four-way dip closure at top-chalk level. It has been induced through salt tectonics by up-doming of the chalk layers over a salt pillow (Klinkby et al. 2005). The main chalk reservoir units are found in the Danian Ekofisk Formation and the Maastrichtian Tor Formation, which are characterised by high porosity (24-32\%) on the crest of the structure and low matrix permeability of less than $1 \mathrm{mD}$ in the Danian and 2-3
$\mathrm{mD}$ in the Maastrichtian units, and an effective permeability of $8-10 \mathrm{mD}$ due to fracturing. The oil zone is characterised by high water content $(>50 \%)$ and limited thickness $(70 \mathrm{~m})$, and the gas cap is thin, less than $8 \mathrm{~m}$. The free water level in the Kraka Field dips to the south-east according to Thomasen \& Jacobsen (1994).

\section{Geophysical interpretation}

Integrating detailed seismic horizon interpretation and gamma-ray $\log /$ sonic-log correlation enables a consistent division of the Chalk Group and correlation of the Chalk Group units between wells in the study area. The interpretation of the gamma-ray $\log /$ sonic $\log$ of the Anne-3 well in the Kraka Field (Figs 1,2) illustrates how reservoir and nonreservoir intervals can be identified. The Maastrichtian units M1 to M4 were described by Klinkby et al. (2005), who interpreted an intra-Maastrichtian seismic horizon (base of unit M4; Fig. 2) as the base of the reservoir interval in the Kraka-Dan area, separating porous chalk from tighter chalk below. As part of a major study of the internal chalk structures in the southern part of the Danish North Sea, several additional seismic horizons have been mapped including a porous unit (M5 on Fig. 2) in the Maastrichtian chalk reservoirs, which is present at a slightly deeper level than the previously interpreted base of the reservoir interval.

The base of the M5 unit is seen as a distinct, relatively highamplitude continuous reflection (trough) in the seismic data. The horizon can be correlated from the Kraka wells to Olga$1 \mathrm{X}$ and the Dan Field wells (M-1X, M-2X, M-8X, M-9X and $\mathrm{M}-10 \mathrm{X})$, where it corresponds to a consistent regional reflection between two intra-Maastrichtian intervals. The reflector marking the base of the M5 unit changes character and becomes weaker towards the north-east in the direction of the Alma-1X and Alma-2X wells. Near the Anne- 3 well and farther to the south-west, it merges with a deeper lying intrachalk seismic horizon (Near Top Hod; Fig. 3). Here, an E-W-striking AI profile crossing the Anne-3 well shows pronounced lateral variability in AI values within the M5 unit. On the eastern flank of the Kraka structure, the M5 unit is dominated by low AI values, corresponding to higher porosities. In general, to the north and to the west the base of the M5 unit separates the porous Maastrichtian units with lower AI values from the underlying units with higher $\mathrm{AI}$ values (Figs 3, 4). 


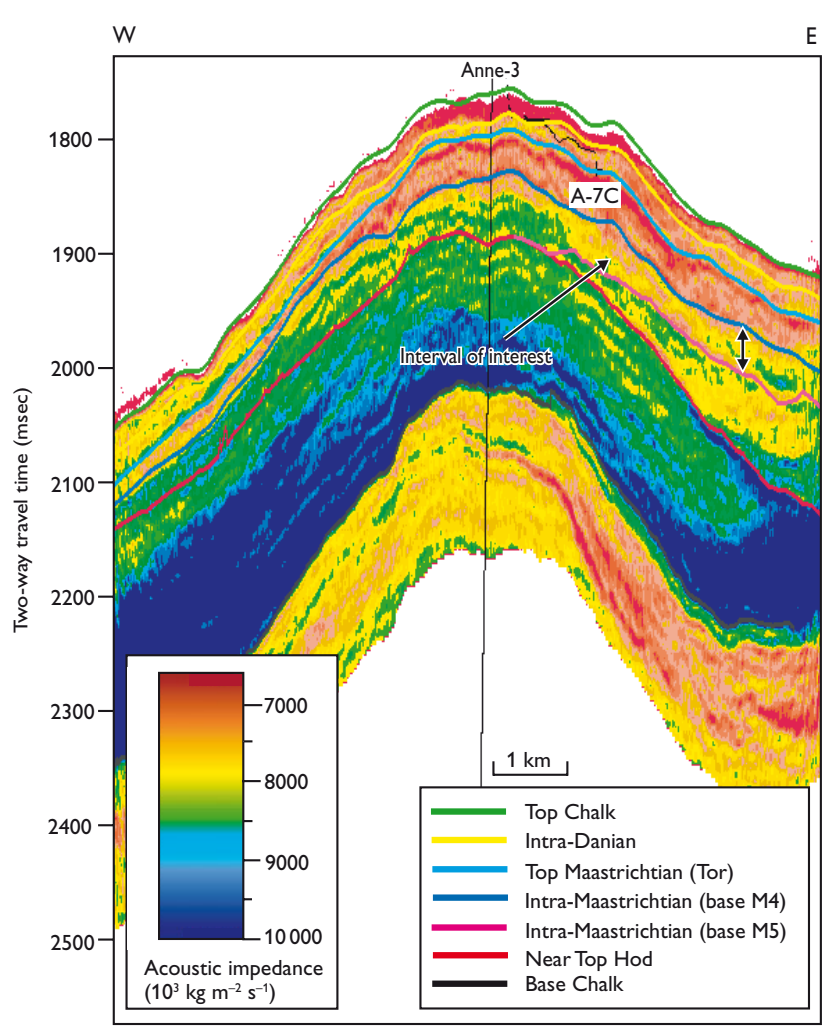

Fig. 3. An E-W-orientated acoustic impedance profile extracted from the inverted seismic data of the merged 3-D survey (produced for Mærsk Oil and Gas AS) crossing the Anne-3 well, Kraka Field.

\section{Transforming acoustic impedance to porosity}

Based on petrophysical log-porosity evaluations of 14 wells from the southern part of the Danish Central Graben, a robust relationship between log-derived AI and PHIT has been established for the Chalk Group (Kristensen \& Andersen 2008). AI can be converted to PHIT using a second order polynomial regression. The following relationship was found for clean chalk ( $<2 \%$ clay) where PHIT is close to the effective porosity (PHIE):

$$
\text { PHIT }=0.729-7.08 \times 10^{-5} \mathrm{AI}+1.55 \times 10^{-9} \mathrm{AI}^{2}
$$

where porosity is given in fraction and $\mathrm{AI}$ in $\mathrm{g} \mathrm{cm}^{-3} \times \mathrm{msec}^{-1}$. In order to display the AI variations of the M5 unit on a map, the lowest AI values were extracted from the inverted seismic data within the target interval. The AI map of the M5 unit shows the presence of an area with low AI values on the south-eastern flank of the Kraka structure (Fig. 5).

The AI-PHIT relationship allowed the generation of a total porosity map (Fig. 6) for the target interval using the seismically derived AI values (Fig. 5). The porosity map shows an area with higher porosities (30-35\%) east of the Anne-3 well on the south-eastern flank of the Kraka struc-

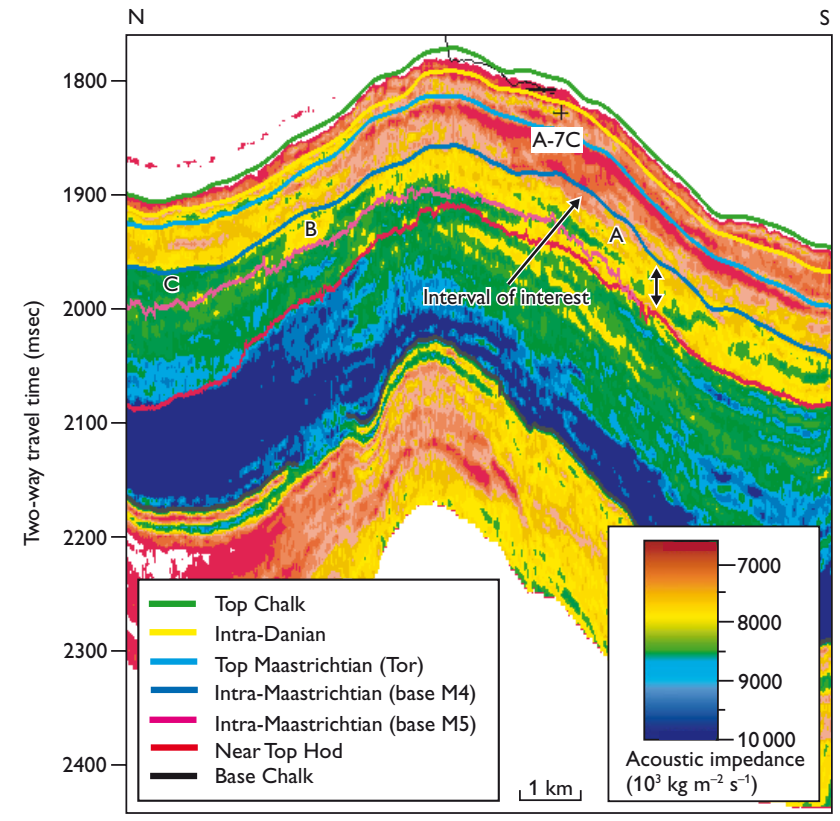

Fig. 4. A N-S-orientated acoustic impedance section from the Dan to Kraka Fields. Labels $\mathbf{A}, \mathbf{B}$ and $\mathbf{C}$ are discussed in the text.

ture. This indicates the existence of high porosity values in the deeper part of the M5 unit. In addition, the seismically derived PHIT values show good agreement with the GR-DT $\log$ values estimated for the M5 unit (Fig. 2).

The area with low AI values (labelled A on the map; Fig. 5) corresponds to label A on the north-south orientated, inverted seismic profile (Fig. 4) and to the high porosity area labelled A' on the porosity map (Fig. 6). The area labelled B on the N-S-orientated inverted, seismic profile (Fig. 4) illustrates the abrupt transition from higher to lower AI values within the mapped unit (equal to B on Fig. 6). This corresponds to an area with relatively low porosity marked by B' on Fig. 6. Similarly, the lower porosities (<25\%) labelled C' on Fig. 6 and located in the saddle between the Kraka and Dan structures correspond to an area with high AI values, labelled C on Figs 4, 5.

\section{Conclusions and outlook}

A multi-disciplinary approach is a powerful method for detecting and predicting intervals of high porosity of chalk in the North Sea. This study indicates the existence of high porosity values at a slightly deeper level than the previously interpreted base of the reservoir interval on the south-eastern flank of the Kraka Field.

A porosity map based on inverted seismic data may contribute as input to a 3-D reservoir model for further calculation of hydrocarbon volumes at different reservoir property and FWL scenarios. 


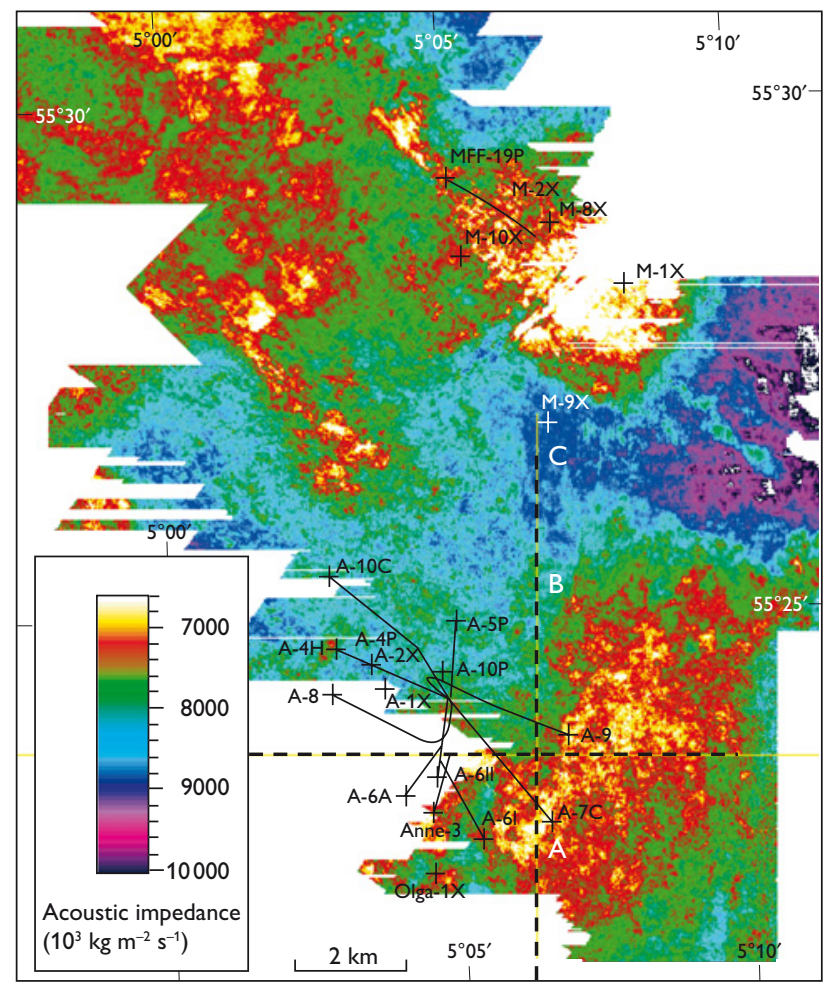

Fig. 5. Map showing the distribution of the lowest acoustic impedance values in unit M5 in the area of the Kraka and Dan fields. Labels A, B and C correspond to the labels on Fig. 4. The black stippled lines show the position of the two profiles shown in Figs 3 and 4. For location see Fig. 1.

\section{References}

Anderson, J.K. 1999: The capabilities and challenges of the seismic method in chalk exploration. In: Fleet, A.J. \& Boldy, S.A.R. (eds): Petroleum geology of North-West Europe. Proceedings of the 5th petroleum geology conference, 939-947. London: Geological Society. Britze, P., Nielsen, E.B., Dahl, N. \& Haug, S. 2000: North Sea chalk porosity resolved by integration of seismic reflectivity and well log data. Abstract P100, 64th EAGE conference \& exhibition, Florence. Abstract P100, 4 pp.

Håkansson, E., Bromley, E.G. \& Perch-Nielsen, K. 1974: Maastrichtian chalk from North West Europe - a pelagic shelf sediment. Special Publication, International Association of Sedimentologists 1, 211-233. Hancock, J.M. 1975: The petrology of the chalk. Proceedings of the Geologists' Association 86, 499-535.

Jørgensen, L.N. \& Andersen, P.M. 1991: Integrated study of the Kraka Field. Society of Petroleum Engineers paper, 14 pp. (http://dx.doi.org/ 10.2118/23082-MS).

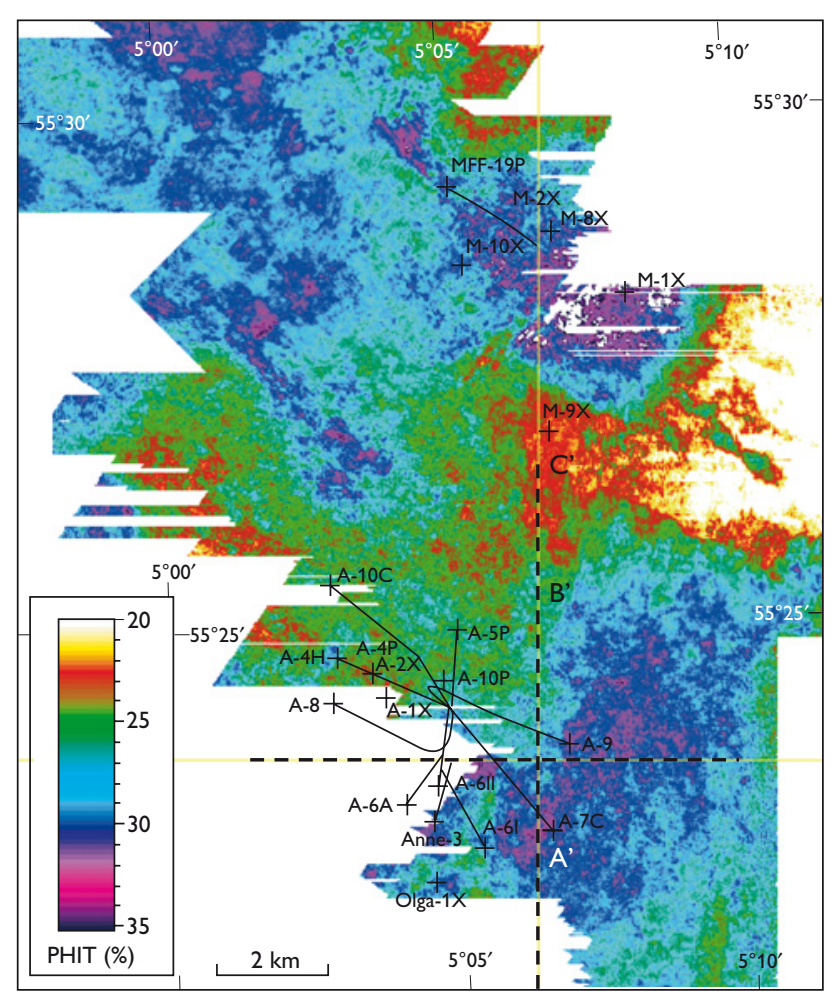

Fig. 6. Porosity map for the M5 unit in the area of the Kraka and Dan fields derived from the AI-PHIT transform. Porosity anomalies labelled A', B' and C' correspond to A, B and C on Figs 4 and 5 as discussed in the text. The black stippled lines show the position of the two profiles shown in Figs 3 and 4. For location see Fig. 1.

Klinkby, L., Kristensen, L., Nielsen, E.B., Zinck-Jørgensen, K. \& Stemmerik, L. 2005: Mapping and characterisation of thin chalk reservoirs using data integration: the Kraka Field, Danish North Sea. Petroleum Geoscience 11, 113-124.

Kristensen, L. \& Andersen, C. 2008: Log-derived acoustic impedance versus porosity and porosity versus depth trends in the Chalk Group: examples from the southern Danish Central Graben. Danmarks og Grønlands Geologiske Undersøgelse Rapport 2008/13, 33 pp.

Thomasen, J.B. \& Jacobsen, N.L. 1994: Dipping fluid contacts in the Kraka Field, Danish North Sea. Society of Petroleum Engineers paper, 10 pp. (http://dx.doi.org/10.2118/28435-MS).

Vejbæk, O.V., Bidstrup, T., Britze, P., Erlström, M., Rasmussen, E.S. \& Sivhed, U. 2007: Chalk depth structure maps, central to eastern North Sea, Denmark. Geological Survey of Denmark and Greenland Bulletin 13, 9-12.

\section{Author's address}

Geological Survey of Denmark and Greenland, Øster Voldgade 10, DK-1350 Copenhagen K, Denmark. E-mail: tab@geus.dk 